\title{
The Required Textbook - Friend Or Foe? Dealing With The Dilemma
}

Deborah Skinner, Butler University, USA

Barbara Howes, Butler University, USA

\begin{abstract}
The use of a required text is an accepted practice in most college courses, but two-thirds of the students are coming to class without reading the textbook, some of them never buying the textbook at all. A review of the literature about textbook usage and student reading habits provides a comparison between how faculty and students view the pros and cons of the required textbook. The analysis suggests faculty and students share the general benefits of textbook usage (e.g., knowledge, consistent material, accessible) but that those benefits are countered by several personal "costs" from the student perspective. The pros and cons are explained and recommendations offered to help deal with students' concerns. A brief consideration of alternative strategies is presented.
\end{abstract}

Keywords: Textbooks; Reading Habits; Textbook Usage; College Students; E-text

\section{INTRODUCTION}

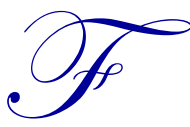

aculty afford significant importance to textbooks as class resources (Chatman and Goetz, 1985). Recent research on textbook usage finds that less than one-third of students are coming to class having read the assigned text materials (Clump, Bauer, and Bradley, 2004; Burchfield and Sappington, 2000). If students are not regularly reading their textbooks, should faculty be so committed to using them? Is the required textbook such an overwhelming "friend" to college faculty that they are willing to invest time and effort to defeat the "foe" status it has with the students in their classrooms? Therein lies the dilemma.

There are many issues to be considered when assigning a textbook for a course. Several studies have been conducted which analyze issues relevant to the usage and selection of textbooks, including important textbook attributes (e.g., accuracy, review questions, author's reputation) and student learning (Landrum and Hormel, 2002), topic coverage, pedagogical aids, core concepts (Griggs and Marek, 2001), and student evaluation of textbooks and readability (Marek, Griggs, and Christopher, 1999; Durwin and Sherman, 2008). Many of these studies deal with psychology texts and are presented from the instructor's perspective with a few adding the importance of student input.

Most of the current literature addresses issues of textbook selection from one perspective - the faculty teaching the course. This article builds on this research and analyzes the pros and cons of textbook usage taking into account both faculty and student perspectives. Further analysis establishes the general nature of the faculty's favorable reasons for using a text versus the personal reasons students cite for avoiding textbooks. A table of comparison is provided. Finally, a discussion of how faculty might deal with issues to help address the dilemma is presented.

\section{THE PROS OF USING A TEXTBOOK - GENERALLY POSITIVE}

There are a number of reasons why a professor might choose to require a textbook in a college course (see Table 1- quadrant A). The issues are mostly general in nature; that is, issues that impact the typical instructor regardless of discipline, nature of the course (i.e., major versus core curriculum), year of the students taking the course (i.e., freshmen versus seniors), or years of experience teaching the course. The issues discussed are the same 
general benefits that students derive from textbook use, although they may not realize these benefits exist. The issues are not presented in any order of importance. Numbers have been included in both the table and the narrative to provide guidance.

Table 1: Comparison of Pros and Cons of Textbook Usage from Instructor and Student Perspectives

\begin{tabular}{|c|c|c|c|c|}
\hline & \multicolumn{2}{|l|}{ Faculty } & \multicolumn{2}{|l|}{ Students } \\
\hline Pros & $\begin{array}{l}\text { General } \\
\text { 1) } \\
\text { 2) } \\
\text { 3) } \\
\text { 4) } \\
\text { 5) } \\
\text { Personal } \\
\text { 6) }\end{array}$ & $\begin{array}{l}\text { A } \\
\text { Provides baseline knowledge } \\
\text { Encourages subject involvement } \\
\text { Facilitates readability and understanding } \\
\text { Meets standards } \\
\text { Offers uniform content and accessibility } \\
\text { over multiple sections and instructors } \\
\text { Contributes ready-made materials and } \\
\text { supplements }\end{array}$ & $\begin{array}{l}\text { General } \\
\text { 1) } \\
\text { 2) } \\
\text { 3) } \\
\text { 4) } \\
\text { 5) } \\
\\
\text { Personal } \\
\text { 7) } \\
\text { 8) }\end{array}$ & $\begin{array}{l}\quad \text { B } \\
\text { Provides baseline knowledge } \\
\text { Encourages subject involvement } \\
\text { Facilitates readability and } \\
\text { understanding } \\
\text { Meets standards } \\
\text { Offers uniform content and } \\
\text { accessibility over multiple sections and } \\
\text { instructors } \\
\text { Represents short- and long-term value } \\
\text { Delivers reliable references }\end{array}$ \\
\hline Cons & $\begin{array}{l}\text { General } \\
\text { Personal } \\
\text { 15) }\end{array}$ & $\begin{array}{l}\quad \text { C } \\
\text { Increases time and effort needed in } \\
\text { textbook selection }\end{array}$ & $\begin{array}{l}\text { General } \\
\text { Personal } \\
\text { 9) } \\
\text { 10) } \\
\text { 11) } \\
\text { 12) } \\
\text { 13) } \\
\text { 14) }\end{array}$ & $\begin{array}{l}\quad \text { D } \\
\text { Increases college expenses } \\
\text { Questions perceived value } \\
\text { Contributes to unmotivated readers } \\
\text { Includes visuals but lacks entertainment } \\
\text { value } \\
\text { Competes for time } \\
\text { Offers minor technological options }\end{array}$ \\
\hline
\end{tabular}

The reason most commonly cited for using a text is that the course textbook serves as a foundation of knowledge and provides uniform content (1) on a given topic (Besser, Stone and Nan, 1999; Cloutier, 2009). A text is "the voice of the discipline" and afforded a high level of credibility (Issitt, 2006, 6). A textbook represents what the "community of scholars" considers to be the domain of a discipline, especially for introductory courses. Many students perceive a text to have been written by "experts" in the field.

Textbooks may provide a greater motivation to become involved with the subject matter (2). Students consider a textbook to be a source of reference to help them think "within" that discipline (e.g., to think as a sociologist) (Best and Schweingruber, 2003). Cloutier (2009, p. 355) suggests that a good textbook is like a good tour guide - something to "inspire a return to the subject matter"

Textbooks are designed to be easier to read, to summarize primary sources, and to use words designed to match students' cognitive abilities and their learning styles (3). Texts are also known to create frameworks (e.g., outlines, chapter themes), thus making it easier to understand complex subject matters.

Many texts have been written to meet the standards required by state or federal mandates or by accreditation agencies (4). An instructor may be directed to use a text based on its predetermined coverage of those standards. In some disciplines, proficiency requirements are established to ensure a level of achieved knowledge. It is necessary to coordinate a textbook with the requirements to ensure students have a reliable reference and resource. 
Using a text as the core resource for a class guarantees all students have access to the same material, thus ensuring consistency across the topics (5). Most students have access to textbooks. The growth of the Internet provides students with the opportunity to browse the used textbook market to purchase online or tablet versions. Using one text over several classes can create a situation where the text authors become the common reference point for the course (Forbes, 2009). This offers a sense of continuity for both students and faculty.

All of these reasons fit a general model of why textbook usage is valuable for both faculty and students (compare quadrants A and B in Table 1). However, these issues are often nebulous, rarely considered as compelling reasons for either the instructors and the adoption of a textbook or for the student as a purchase requirement.

Some issues provide a more personal reason for requiring a textbook. Personal, in this case, applies to issues that directly impact an instructor or student, individually. This means issues that an instructor (student) chooses to address or ignore depending on his/her personal preference. From the instructor's perspective, using a textbook in a course may include ready-made information and materials that are provided by publishers (6). The materials offered as supplements of textbooks mean the instructor has immediate access to resources for teaching methods and practical application (e.g., cases, websites). The resources may be helpful to the novice instructor who might use the text to aid in course design or the first time instructor that is not familiar with examples, activities, etc. Even veteran instructors may benefit from labor-saving, turn-key lectures and examination materials as they encounter more and more pressure to teach more and different classes. An instructor may be a specialized expert in her discipline and find that an introductory text provides a broad overview. As a resource, a text is often said to be presented in an unbiased way and therefore can help to suggest a level of credibility to the materials not immediately afforded the teacher (Blanchard, 2009). Some faculty may find the plethora of supplemental materials to be the deciding factor in whether or not to utilize a textbook in their classes.

There is no such equivalent reason for students. Other than solution manuals and online self-administered activities, students have little concern for the peripherals that are offered to their teachers for help with instruction. Students may value the variety of examples or activities an instructor employs in class; however, they are not likely to attribute those to the chosen textbook.

From a personal standpoint, students purchase, read and retain their textbooks based on the perceived value of the text (7). If the perceived benefits (e.g., securing a better grade, use as a future reference) outweigh the original cost and the potential resale value, students should be willing to purchase the text as a valued resource. Unni (2005) found there to be both short-term and long-term benefits to textbooks from the students' perspective. Short-term benefits result when textbooks usage is linked to assignments and exams, creating situations where reading or studying the text results in improved grades. Long-term benefits include the relevance of the text for future use beyond college, the contribution of the text to retaining course material, and the resulting perceived value of the text. Students in the Unni study assigned greater perceived value to textbooks in their major and were likely to retain those texts rather than sell them back to the bookstore.

Some students regard a textbook as a necessity, an accepted part of a course, and a valued aid for learning, reference, review, and exam preparation (8). Textbooks make it easy to focus on important concepts with bolded text and margin definitions. Often, the text takes the place of the instructor when a student is outside the classroom.

Although several positive reasons exist for requiring a textbook in a college course, all but a few of the reasons, from both an instructor's and a student's perspective, involve general benefits rarely consciously recognized. The decision to use a text based on the complementary materials offered by the publisher may be a valid reason for choosing to require a course textbook, but it is a reason that relates directly to the benefits sought by the instructor and indirectly to what individual students might gain. On the other hand, many students seem to have developed a dependency on textbooks to provide guidance and direction which may be the reason they choose to acquire the textbook for a course.

In contrast to the pros of requiring a text for a class, one can also generate a list of cons against textbook usage, especially from the students' perspective. These will be discussed in the next section. 


\section{THE CONS OF USING A TEXTBOOK - PERSONALLY NEGATIVE}

The negative aspects of using a required textbook in class appear to be heavily weighted on the students' side and from a more personal impact (refer to quadrant $\mathrm{D}$ in Table 1). The negative issues from the student perspective may create repercussive negatives for the instructor as she has to deal with student complaints and frustrations. Each negative issue will be discussed from the student's perspective. These include concerns such as cost, motivation, need for entertainment, time, and technology. Any or all of these issues may serve as the impetus for the lack of textbook involvement (i.e., purchasing or reading).

The exorbitant cost of texts is increasingly becoming an issue which impacts students' decisions whether or not to purchase the textbook (9). The price tag can be perceived as excessive. Publishers include supplemental materials (e.g., study guides, manuals) to entice faculty. These added costs are passed on to the students. The average cost of books and supplies at a four-year university during 2012 and 2013 was estimated to be $\$ 1,200$ at public colleges and \$1,244 at private colleges (Average Estimate, 2012).

Students are also interested in the residual value of the textbook. Some students are interested in the resale price they might earn at the end of the semester when bookstores make buyback offers (10). Publishers insist on frequent new editions which limit the opportunity for finding used books or reselling a book back after a semester's use. Some publishers admit to the planned obsolescence of texts in order to deal with the increasing competition created by the used textbook market (Iizuka, 2007). On the other hand, if a textbook is considered a valuable resource for future reference, a student may make the initial purchase given the perceived long-term value.

Students are frequently unmotivated to read their assignments (11), some due to a tendency to procrastinate or to schedule last-minute cramming. Other students have a lack of self-confidence in their ability to read and comprehend the material (Ryan, 2006; Paulson, 2006). In a study of readers and non-readers of assigned reading, Hoeft (2012) found non-readers claimed they would be more likely to read if professors would give "1) quizzes, 2) supplemental assignments, and 3) frequent reminders about the interesting assignment that was due" (Hoeft, 2012, 9). In a subsequent study, she found that quizzes and assigned journal questions, in conjunction with the reading, were helpful at increasing reading compliance. However, reminding the students of the assignments did nothing to increase the number of students that read (Hoeft, 2012). Students may be less compliant with assignments as they do not realize the significance of the content to their learning (Sikorski, et al., 2002). Students claim to be more motivated to read when they are given more direction from faculty on what to read (Berry et. al, 2010). Lumsden (1995) found that students who are intrinsically motivated or interested in the subject matter are more likely to read the text. Unfortunately, students are not as interested in all subject matters (e.g., core curriculum required courses) and therefore discount the value of the assignment and the potential for learning from the textbook.

Many students grew up on 30 second Sesame Street sound bites and fast action video games and therefore want quick reads and highly illustrated texts. This suggests that textbooks need to be perceived for their entertainment value and not their education value (12). Some textbooks are complying with student demands and are going to a "magazine look" with visuals to help reinforce the main points (Socash, 2007). More texts are increasing the number of pages of visual elements, including photography, figures and tables. However, these visuals may come at the expense of explanations or in addition to the actual writing, adding costs to the production, making prices even higher. The additional images may be motivating to those students with a visual learning style (Shepherd and Mullane, 2010), but there is a significant leap to the idea that a textbook, regardless of the number of visuals, could ever be considered an "entertainment" source.

More students are reporting that lack of time is an issue in whether they read their textbooks (13). Phillips (2010) claims the average Millennial spends 50 minutes a day reading. She says that Gen Y is mostly reading for the purpose of collecting information and that they have become very good at scanning rather than reading in depth. Their sources of information may be the typical outlets - newspapers, magazines, news shows - but it all comes via access to the internet and websites that have condensed stories, quick read paragraphs, headlines or picture captions. One might conclude that very few of the 50 "reading" minutes are spent reading textbooks. 
In Berry, et al. (2010), 92\% of the students surveyed reported reading their textbook less than three hours a week and $18 \%$ reported never reading the book. Students reported that they minimize their reading to "essential" parts due to the constraints on time (e.g., course loads, work, and activities). They also cited an overload of weblinks, tutorials, videos, and study problems. With limited amounts of time and no direction on where to focus their efforts, some students reported giving up (Berry, et al., 2010).

Finally, these students are connected via technology with people all over the world. Their sense of important information comes in much smaller amounts (e.g., Twitter) rather than a 25-page textbook chapter. A textbook is static, unchanging and without buttons to push or screens to slide; turning a page no longer represents interactivity (14). Contemporary students have a need to be engaged kinetically all the time and a 500-page textbook does not fit that requirement. Some textbook publishers are including online options to meet students' expectations. Homework, study guides and problem answers are all available through internet access.

Electronic versions of textbooks present a two-edged sword. Over half of the current textbook publishers offer e-books but they are too much like traditional text in digital format (Young, 2009). It does not appear that an online textbook will be read any more often than the hard copy. As studies show, people prefer reading the paper version of the text rather than an on-screen version (e.g., Allen, 2008). Even when assigned online reading, Spencer (2006) found that the majority of students printed out the material. Over half the respondents in Allen's study (2008) purchased a physical text even when they could use a free online version. Woody, Daniel and Baker (2010) compared e-book readers with non e-book readers and found little difference in learning outcomes. However, the groups reported using the books differently. Those reading print books reported reading captions and charts and having a higher level of satisfaction than those reading e-books. Readers have less confidence in their learning with e-books (Noyles and Garland, 2003), so, although students prefer technology over the more traditional way of obtaining information, they do not read any more often - and possibly less often - when the textbook is in e-format. A textbook is still a textbook whether on a computer screen or in a physical page-turning format.

Several negative concerns exist for students regarding the use of a college textbook in a course. For the student, these concerns are of a personal nature and it only takes one reason to limit either the purchase or interaction with a required course textbook.

A negative issue facing college instructors regarding college textbook usage is also personal in nature and concerns the time and effort it takes to choose a text. In order to encourage students to purchase and read the assigned textbooks, instructors may have to add to their list of necessary selection criteria (e.g., visual appeal, price). With the normal pressures of teaching, research and service, most faculty are already facing constraints on their available time.

\section{DEALING WITH THE DILEMMA}

How might faculty reconcile the generally positive reasons for using a textbook with the students' personal reasons for rejecting a textbook? Remedies are offered to address each of the negative student issues.

\section{Prices}

Students are not the only ones to react to high textbook prices. U.S. lawmakers were prompted to take action to curb the spiraling costs of college textbooks. As of July 2010, federal law requires publishers to provide faculty with textbook pricing information and to unbundle texts from supplementary materials such as study guides. Colleges are then required to include the pricing information in the course syllabus along with the ISBN (Smith, 2010). Silver, Stevens and Clow (2011) found that over $86 \%$ of surveyed marketing professors had heard complaints from students about the cost of textbooks, but that most faculty felt negatively about legislation and policy set up to control textbook costs.

If faculty consider a text to be critical to students' success in a course, it seems imperative that they seek pricing figures when selecting the best text for their course and to weigh the value of adopting new editions. It may mean adhering to university policy changes, such as a mandated minimum three-year text usage or required adoption 
of lowest cost text (Iizuka, 2007). This adds time, effort and potential frustration to the process of text selection and new criteria for consideration - student price, resale value, and likelihood of a new edition.

\section{Perceived Value}

Faculty can often influence their students' perceptions of textbook value. First, when choosing a text for class, the instructor should consider the students' needs as well as his own (e.g., inclusion of glossary, use of text knowledge in subsequent courses, value as future reference). If the text is considered important enough to require purchase, it should at least be referenced by the instructor in discussion and/or exams to demonstrate its importance in the students' learning process. Faculty may need to reinforce the use of textbook assignments as a helpful method to develop crucial learning skills such as critical thinking, analysis, and comprehensive understanding. It might be helpful to offer a reminder that the students' future job experiences are likely to require similar skills as they will read detailed and "boring" reports and work-related materials.

\section{Motivation}

Given the likelihood of encountering a portion of students that are unmotivated to read, the faculty might closely examine all the reading assignments. Are there materials that are less important to learning? Are there other resources that might be more useful in transmitting the materials (e.g., Internet options)? Are there places where assignments can be trimmed back to include only the essentials? It may be that reviews are warranted every semester and it may be of value that teachers ask students for direct feedback on textbooks.

Instructors can help motivate their students to read by providing rewards or incentives (Hoeft, 2012; Ryan, 2006). Tying the reading assignments to quizzes, exam questions, and/or discussion points is helpful for those students who are extrinsically motivated by things such as final course grades. Students may not be able to make clear connections between lectures/discussion and sections from the text. The instructor might encourage students to record book sections or pages in their notes during the discussion to help emphasize association between the class material and the textbook. Faculty may provide an in-class demonstration of expectations for reading comprehension or recommendations for reading practices to help increase reading confidence. These remedies are likely to be helpful in motivating students to engage more fully with their textbooks but require additional time and attention by faculty.

\section{Visual Stimulation and Entertainment}

Faculty should consider textbooks for the visual elements they offer the students. Students are more willing to read when the materials are offered in the format and style that they are accustomed to reading. Textbook scrutiny for visual appealing elements may add time to the selection process, but most publishers are already making it easier for faculty to comply with this requirement. It is doubtful that any instructor could sell a textbook as a form of "entertainment", nor should that be the goal.

\section{Time}

Faculty has little control over how students spend their time outside of class. It is not suggested here that faculty cut back on the reading assignments to give students more time to participate in work or extracurricular activities. If a text assignment has been selected because of its importance to learning and understanding the subject matter, then faculty has a responsibility to convey that to the students to reinforce that reading will be a good use of their time. In reviewing assignments and readings, a faculty member might also estimate the time required to complete the assignment. Are the instructor's expectations in line with the actual time required to complete by the students? What makes for the best use of time both inside and outside the classroom for both parties?

\section{Technology}

Faculty must review the technology options when considering text selection. Today, students are immersed in technology. Faculty should review how technology can be used to supplement and enhance the material. Online 
activities offer a way to motivate the students to be involved in the subject matter using an interactive format and may encourage students to read the textbook for support (see Courts and Tucker, 2012, for suggestions on how to integrate technology into the classroom). Publishers of textbooks are helping with this initiative by offering interactive websites and activities along with the textbook.

\section{WHERE TO GO FROM HERE?}

As the discussion suggests, routine use of a required course textbook can be either endorsed because of the general and well-intended supportive arguments for its usage or disputed because of personal dissenting arguments against it. The debate of textbook usage raises questions for both faculty and students to consider. Should instructors continue to use the traditional textbook in all classes? Should they move to an e-text? Should they dispense with textbooks in some courses altogether? Will focused attention to motives and value increase the number of students reading? Do visual and/or online materials improve student interaction with the materials?

\section{Require A Textbook But...}

A text does not have to be an end in itself. There are several options one might consider if textbook usage is still considered crucial. The easiest, of course, and the one most often followed by faculty, is to solicit textbooks from the multitude of publishing companies, review the text and the supplemental materials, and choose the one that supports the learning objectives of the course and the needs of the faculty member. This would be considered the traditional response to course preparation but might include consideration of the recommendations above to deal with the negative issues conveyed in this discussion (e.g., visual displays, textbook prices). This requires additional time and effort on the part of the faculty but increases the likelihood of a more positive student response to reading textbook assignments.

Customizing a text is an appealing option to some. Most publishers are presenting faculty with custom publishing options where they select only the material of interest from a text with the opportunity to add additional content. This allows the instructor some degree of flexibility and freedom in the choice of materials but also provides the structure, frameworks and credibility that students find positive about textbooks.

A third option, requiring considerably more work, is to write one's own text for classroom use. This option guarantees that the necessary topics will be covered, but it presents its own negatives - in order for a text to sell it must be attractive to others in the field. In designing one's own textbook, the negative student concerns could be addressed as one was preparing the materials and assignments for inclusion.

\section{Don't Require A Text...}

There is always the option to abandon the textbook altogether. A textbook does not need to be the only source for reading materials. Popular press outlets (e.g., Wall Street Journal), Internet sources (e.g., TED videos), and social media (e.g., Skype) provide substitute options. There are campus-wide resources that faculty can tap into should they choose to venture away from the textbook. Many faculty have access to a reference librarian devoted to his or her discipline that might be helpful in search for resources. Instructional technology departments offer collaborative partnering to assist faculty with technology resources. The faculty from the School of Education may be enlisted to provide guidance to faculty on resources and methodologies that might be relevant substitutes. This route is extremely time consuming and not recommended for new faculty. However, it can aid the instructor in getting current in his discipline and developing knowledge in the world of technology. It also lends itself to learning in a way similar to how students are engaged in the process and it provides direct insight to their criticisms.

\section{CONCLUSION}

There are crucial times when a required text is necessary, but for many faculty members, a textbook requirement is assumed and selection criteria are limited to what has been used before. This article points out that a textbook is generally used as a resource of information, meant to provide consistency and access to students. Textbooks prove invaluable when a baseline of knowledge is needed or when a novice instructor is teaching the course. They may also serve as a ready reference for students. 
Choosing a textbook is not an easy process. There are issues an instructor should consider from a student's perspective. Faculty must review pricing information and include the price in their syllabi. They should consider the value of the text from a long-term perspective and not just the immediate requirements. The instructor should review: 1) the purpose/motivation behind assigned readings, 2) the inclusion of text materials in discussions/exams, 3 ) the use of supplemental materials, and 4) his role in motivating the student to read. Instructors should consider the role of visual elements in enhancing understanding. The role of technology must also be considered, including such issues as the availability of multiple formats (e.g., hard copy, e-book) and the inclusion of the Internet.

Faculty have many options when it comes to text selection, including customizing a text with the publisher's assistance, writing their own book to facilitate learning, using materials from other secondary sources, or taking advantage of various resources across campus (i.e., librarians, IT personnel, colleagues). Faculty should review the automatic use of textbooks in their courses. Some classes warrant the inclusion of a required textbook, but selection of the appropriate text must take into consideration the perceptions and needs of today's students. The appropriate choice may mean a better chance for successful student learning.

\section{AUTHOR INFORMATION}

Deborah Skinner is an associate professor of Marketing at Butler University specializing in advertising and strategy. Her research interests focus mainly on pedagogical issues in higher education and consumer consumption practices. E-mail: dskinner@ butler.edu (Corresponding author)

Barbara Howes is the Science Librarian at Butler University.

\section{REFERENCES}

1. Allen, N. (2008). Course correction: How digital textbooks are off track and how to set them straight. Chicago: Student PIRGS. Retrieved from: http://www.studentpirgs.org/sites/student/files/reports/course correction_3.pdf

2. Average Estimated Undergraduate Budgets, 2012-13. Trends in Higher Education. The College Board, Annual Survey of Colleges. Retrieved from: http://trends.collegeboard.org/college-pricing/figurestables/average-estimated-undergraduate-budgets-2012-13

3. Berry, T., Cook, L., Hill, N., \& Stevens, K. (2010). An exploratory analysis of textbook usage and study habits: Misconceptions and barriers to success. College Teaching 59(1) 31-39.

4. Besser, D., Stone, G., \& Nan, L. (1999). Textbook and teaching: A lesson from students. Journalism \& Mass Communication Educator 53(4) 4-17.

5. Best, J. and Schweingruber, D. (2003). First words: Do sociologists actually use the terms in introductory textbooks' glossaries? The American Sociologist 34(3) 97-106.

6. Blanchard, K. D. (2009). Accepting our limitations: the textbook as crutch and compromise. Teaching Theology \& Religion 12(3) 252-53.

7. Burchfield, C.M. \& Sappington, J. (2000). Compliance with required reading assignments. Teaching of Psychology 27(1) 58-60.

8. Chatman, S. P. \& Goetz, E. T. (1985). Improving textbook selection. Teaching of Psychology 12(3) 130152.

9. $\quad$ Cloutier, D. (2009). Yes, I use a textbook. Teaching Theology \& Religion 12(4) 254-55.

10. Clump, M.S., Bauer, H. \& Bradley, C. (2004). The extent to which psychology students read textbooks: A multiple class analysis of reading across the psychology curriculum. Journal of Instructional Psychology 31(3) 227-232.

11. Courts, B. \& Tucker, J. (2012). Using technology to create a dynamic classroom experience. Journal of College Teaching \& Learning, 9(2) 121-127.

12. Durwin, C. C. \& Sherman, W. M. (2008). Does choice of college textbook make a difference in students' comprehension? College Teaching 56(1) 28-34.

13. Forbes, B. D. (2009). Textbooks in the introductory course. Teaching Theology \& Religion 12(3) 256-57.

14. Griggs, R. A., \& Marek, P. (2001). Similarity of introductory psychology textbooks: Reality or illusion? Teaching of Psychology 28(4) 254-56. 
15. Hoeft, M.E. (2012). Why university students don't read: what professors can do to increase compliance. International Journal of Scholarship of Teaching and Learning 6(2) 1-19. Retrieved from: http://academics.georgiasouthern.edu/ijsotl/v6n2.html

16. Iizuka, T. (2007). An empirical analysis of planned obsolescence. Journal of Economics \& Management Strategy 16(1) 191-226.

17. Issitt, J. (2006). Reflection on the study of textbooks. History of Education 33(6) 683-96.

18. Landrum, R. E. \& Hormel, L. (2002). Textbook selection: balance, between the pedagogy, the publisher, and the student. Teaching of Psychology 29(3) 245-48.

19. Lumsden, L.S. (1995). To learn or not to learn: understanding student motivation. OSSC Report 35(2) (ED380883). Retrieved from http://www.eric.ed.gov/PDFS/ED380883.pdf

20. Marek, P., Griggs, R.A., \& Christopher, A. N. (1999). Do college students' perceptions justify their prevalence? Teaching of Psychology 26(1) 11-19.

21. Noyles, J.M. \& Garland, K. J. (2003). Students' attitudes toward books and computers. Computers in Human Behavior, published online 17 April 2004 doi:10.1016/j.chb.2004.02.016.

22. Paulsen, E. J. (2006). Self-selected reading for enjoyment as college developmental reading approach. Journal of College Reading and Learning 36(2) 51-58.

23. Phillips C. (2010). Do millennials read? Yes but they read differently. Millennial Marketing blog. Retrieved from http://www.millenialmarketing.com/2010/05/do-millenials-read-yes-but-they -readdifferently/

24. Ryan, T.E. (2006). Motivating novice students to read their textbooks. Journal of Instructional Psychology 33: $135-140$.

25. Shepherd, C. \& Mullane, A. M. (2010). Managing multimedia mania: Taming the technology beast. Journal of College Teaching and Learning 7(1) 59-70.

26. Sikorski, J. F., Rich, K., Saville, B.K., Buskist, W. Drogan, O. \& Davis, S.F. (2002). Student use of introductory texts: Comparative survey findings from two universities. Teaching Psychology 29(4) 312313.

27. Silver, L. S., Stevens, R.E., \& Clow, K.E. (2011). Marketing professors' perspectives on the cost of college textbooks: a pilot study. Journal of Education for Business 87(1) 1-6.

28. Smith, D. (2010). New federal rules take aim at college textbook costs. The Fort Worth Star; July 22. Retrieved from: http://www.mcclatchydc.com/2010/07/22/97931/new-federal-rules-take-aim-at.htm

29. Socash, R. R. (2007). Adjusting lecture style to accommodate student reading habits. Journal of College Teaching \& Learning 4(2) 59-64.

30. Spencer, C. (2006). Research on learners' preference for reading from a printed text or from a computer screen. Journal of Distance Education 21(1) 35-52.

31. Unni, R. (2005). Value perceptions and retention of textbooks among marketing and other business majors. Marketing Education Review 15(2) 71-79.

32. Woody, W. D., Daniel, D.B., \& Baker, C.A. (2010). E-books or textbooks: students prefer textbooks, Computers \& Education 55(3) 945-948.

33. Young, M. R. (2009). This could be the year of e-textbooks. Chronicle of Higher Education 56: A1, A2. Retrieved from: http://chronicle.com/article/The-Year-of-e-Textbooks-/48305/ 
NOTES 